\title{
Transistor Probes Local Potassium Conductances in the Adhesion Region of Cultured Rat Hippocampal Neurons
}

\author{
Stefano Vassanelli and Peter Fromherz \\ Department of Membrane and Neurophysics, Max-Planck-Institute for Biochemistry, \\ D-82152 Martinsried/München, Germany
}

Adhesion interactions of neurons in a tissue may affect the ion conductance of the plasma membrane, inducing selective localization and modulation of channels. We studied the adhesion region of cultured neurons from rat hippocampus as a defined model where such effects could be observed electrophysiologically, taking advantage of extracellular recording by a transistor integrated in the substrate. We observed the $\mathrm{K}^{+}$current through the region of soma adhesion under voltage-clamp and compared it with the current through the whole cell. We found that the specific A-type conductance was depleted, even completely, in the region of adhesion, whereas the specific K-type conductance was enhanced up to a factor of 12 . The electrophysiological approach opens a new way to investigate targeting of ion channels in the cell membrane as a function of adhesion processes.

Key words: transistor; potassium; conductance; channel, localization; A-type; K-type; adhesion
Specific sorting of potassium conductances in the plasma membrane is essential for the integrative properties of hippocampal neurons (Storm, 1990; Debanne et al., 1997; Hoffman et al., 1997; Magee, 1998; Martina et al., 1998). Biochemical and genetic studies suggest that voltage-gated ion channels are localized in appropriate domains through direct or indirect interactions with extracellular adhesion molecules (Isom et al., 1995; Irie et al., 1997; Sheng and Wyszynski, 1997; Thomas et al., 1997; Zito et al., 1997). Until now, however, it was not possible to measure the local electrophysiological properties of the cell membrane in a region of adhesion.

With respect to the complex cell-cell and cell-extracellular matrix contacts in vivo, neurons cultured on a coated solid substrate represent a simple model in which the membrane interacts with known adhesion molecules. In the present paper we examine the following question: are there different ion conductances on the upper and lower membrane of a neuron in culture that are exposed, respectively, to the culture medium on one side and in contact with the substrate on the other side? To answer the question, the membrane conductance of the attached membrane of a cultured neuron was studied without disturbing its adhesion to the substrate. We took advantage of the novel method of transistor recording (Fromherz et al., 1991; Fromherz, 1999). There a field-effect transistor is integrated in a silicon substrate beneath a continuous surface of inert silica. It detects the local extracellular voltage in the cleft between the substrate and a cultured cell as it arises from ionic currents through the adherent cell membrane that flow along the resistance of the cleft (Schätz-

\footnotetext{
Received March 18, 1999; revised May 20, 1999; accepted May 27, 1999.

This project is supported by a generous grant of the Bundesministerium für Bildung und Forschung to P.F. We thank Doris Eckerlein for most skillful culturing of the neurons, Bernt Müller for the fabrication of the chips, and Helge Vogl for help with electronmicroscopy.

Correspondence should be addressed to Dr. Peter Fromherz, Department of Membrane and Neurophysics, Max-Planck-Institute for Biochemistry, D-82152 Martinsried/München, Germany.

Copyright (C) 1999 Society for Neuroscience $0270-6474 / 99 / 196767-07 \$ 05.00 / 0$
}

thauer and Fromherz, 1998; Vassanelli and Fromherz, 1998). We chose cultured neurons from rat hippocampus (Banker and Cowan, 1977). They had been characterized in detail with respect to their potassium currents by impaled microelectrodes (Segal and Barker, 1984; Segal et al., 1984) and by whole-cell patchclamp (Ficker and Heinemann, 1992; Klee et al., 1995, 1997). We focused on the fast-inactivating A-type and the slow-inactivating K-type currents, which were discriminated by electrophysiological and pharmacological methods (Storm, 1990; Ficker and Heinemann, 1992; Klee et al., 1995). These currents seem to be related to the expression of various voltage-gated potassium channels (Sheng et al., 1992, 1994; Maletic-Savatic et al., 1995; Veh et al., 1995; Bossu and Gähwiler, 1996; Murakoshi and Trimmer, 1999).

\section{MATERIALS AND METHODS}

Neurons. Neurons were dissociated from the hippocampi of Wistar rats (Thomae, Biberach, Germany) at $18 \mathrm{~d}$ gestation (Banker and Cowan, 1977). They were preplated twice to get rid of glia cells and suspended in DMEM with glutamax I (no. 61965026, Gibco, Eggenstein, Germany) supplemented with $10 \%$ (vol) fetal bovine serum (10106078, Gibco) and $1 \%$ (vol) penicillin (15140114, Gibco) (Brewer et al., 1993; Vassanelli and Fromherz, 1998). The final concentration was 350,000 cells per milliliter.

Cell culture on chips. A chamber of perspex (bottom diameter $3 \mathrm{~mm}$ ) was attached to a silicon chip $(1 \mathrm{~cm} \times 1 \mathrm{~cm})$ with integrated transistors. The surface of the chip was wiped carefully with a $1 \%$ solution of a liquid dish detergent, rinsed with milli-Q water (Millipore, Bedford, MA), dried, and sterilized with UV light. The chips were coated with poly-Llysine (molecular weight $>300,000$; Sigma, Heidelberg, Germany) by adsorption from a $20 \mu \mathrm{g} / \mathrm{ml}$ aqueous solution for $1 \mathrm{~h}$ and dried. Fibronectin (Sigma) was adsorbed from a $10 \mu \mathrm{g} / \mathrm{ml}$ solution in PBS at $4^{\circ} \mathrm{C}$ overnight, with subsequent rinsing. We applied $350 \mu \mathrm{l}$ of the cell suspension to a chamber. Leibovitz L-15 medium (100 $\mu$ l) with glutamax I (31415029, Gibco) supplemented with 5\% fetal bovine serum were added. The density of cells was $\sim 100,000 \mathrm{~cm}^{-2}$. The chips were kept at $37^{\circ} \mathrm{C}$ and $10 \% \mathrm{CO}_{2}$ for $2 \mathrm{~h}$. Then the medium was removed, and the cells were cultured in a serum-free medium (Brewer et al., 1993; Evans et al., 1998; Vassanelli and Fromherz, 1998) using $450 \mu \mathrm{l}$ neurobasal medium (Gibco, 21103049) supplemented with 2\% (vol) B27-medium (17504036, Gibco) and 1\% (vol) glutamax I (35050038, Gibco) for 4-7 d. The density of cells was $\sim 100,000 / \mathrm{cm}^{2}$. The measurements were performed with 


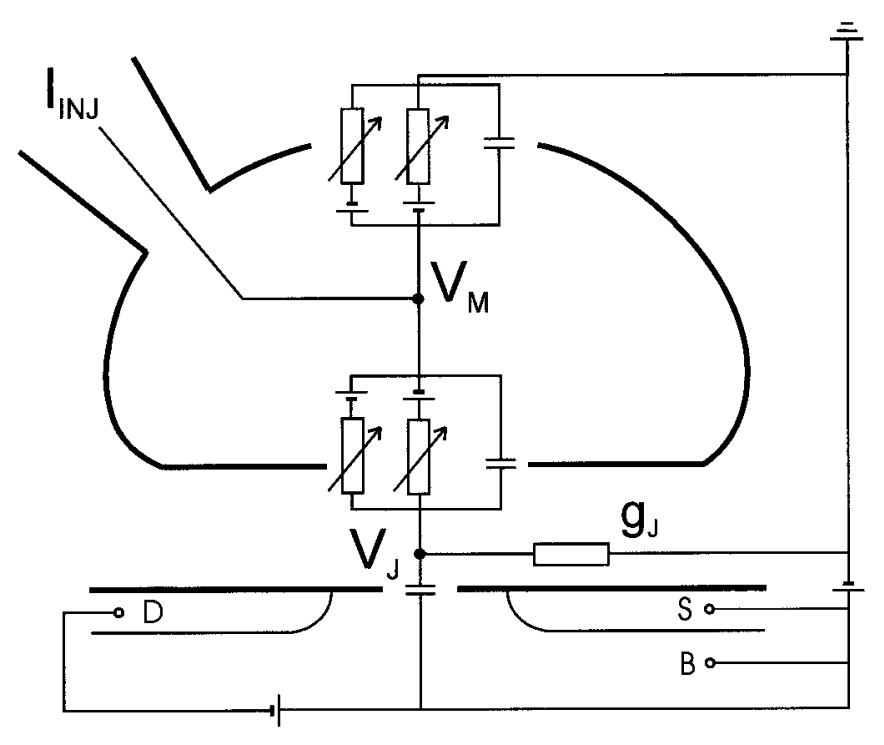

Figure 1. General scheme of transistor recording. The cell membrane with patch pipette and the silicon dioxide on the silicon chip are marked as heavy lines. The actual width of the cleft between oxide and membrane is $\sim 35-70 \mathrm{~nm}$. P-type source $(S)$ and drain $(D)$ of the transistor are in a bulk substrate $(B)$ of n-type silicon with appropriate bias voltages. The modulation of the source drain current probes the extracellular voltage $V_{\mathrm{J}}$ in the cleft. The intracellular voltage $V_{\mathrm{M}}$ is measured and controlled through a patch pipette with an injection current $I_{\text {INJ }} g_{\mathrm{J}}$ is the seal conductance of the junction per unit area. The current balance is described by a two-compartment circuit with capacitances and voltagedependent conductances of the free and of the attached membrane driven by reversal voltages, and with a capacitance of the silicon dioxide.

neurons maintained for a minimum of $4 \mathrm{~d}$ to a maximum of $7 \mathrm{~d}$ in culture when the number of glia cells was still small. The electrophysiological and pharmacological characteristics of the conductances were in agreement with other preparations (Ficker and Heinemann, 1992).

Electronmicroscopy. The cells cultured on the silicon chips were fixed by a slow, drop-by-drop addition of $2.5 \%$ glutaraldehyde in $150 \mathrm{~mm}$ sodium cacodylate buffer, $\mathrm{pH}$ 7.4, for $1 \mathrm{~h}$ (Rothman and Cowan, 1981). The fixation was performed at room temperature. After washing in 150 $\mathrm{mm}$ cacodylate, the specimen was refrigerated for $3 \mathrm{~d}$. It was then post-fixed with $1 \%$ osmium tetroxide in $100 \mathrm{~mm}$ cacodylate for $1 \mathrm{~h}$ at $4^{\circ} \mathrm{C}$, rinsed with $100 \mathrm{~mm}$ cacodylate and double-distilled water, and dehydrated by the gradual addition of acetone. After critical-point drying with liquid carbon dioxide, the cells were coated with gold and examined with a scanning electron microscope (SM300, Topcon, Tokyo, Japan).

Extracellular and intracellular recording. A calibrated transistor records the extracellular voltage $V_{\mathrm{J}}$ in the cleft between the silica surface and the attached cell as illustrated in Figure 1. This voltage in the junction arises from the current flowing along the cleft to the bath. The intracellular voltage $V_{\mathrm{M}}$ is controlled by the injection current $I_{\mathrm{INJ}}$ through a patch pipette. The current balance is described by a two-compartment circuit as shown in Figure 1 (Fromherz et al., 1993; Weis and Fromherz, 1997; Schätzthauer and Fromherz, 1998; Vassanelli and Fromherz, 1998) (point-contact model). Under voltage-clamp, the voltage in the junction $V_{\mathrm{J}}$ is determined by the current through the specific conductances $g_{\mathrm{JM}}^{\mathrm{i}}$ of the membrane in the junction with the reversal voltages $V_{0}^{i}$ and the specific conductance of the cell-silicon junction $g_{\mathrm{J}}$ (total conductance of the cleft divided by contact area):

$$
g_{\mathrm{J}} V_{\mathrm{J}}=\sum_{\mathrm{i}} g_{\mathrm{JM}}^{\mathrm{i}}\left(V_{\mathrm{M}}-V_{0}^{\mathrm{i}}\right)
$$

Equation 1 is valid for weak coupling when the extracellular signal is small and when the reversal voltages $V_{0}^{i}$ are identical in the attached and free membrane (Fromherz, 1999). The injection current $I_{\text {INJ }}$ through the pipette is given by the average specific conductances $\bar{g}_{M}^{\mathrm{i}}$ of the membrane according to Equation 2 with the area $A_{\mathrm{M}}$ of the cell membrane:

$$
\frac{I_{\mathrm{INJ}}}{A_{\mathrm{M}}}=\sum_{\mathrm{i}} \bar{g}_{\mathrm{M}}^{\mathrm{i}}\left(V_{\mathrm{M}}-V_{0}^{\mathrm{i}}\right) .
$$

A simultaneous measurement of $V_{\mathrm{J}}$ and $I_{\mathrm{INJ}}$ with known scaling factors $g_{\mathrm{J}}$ and $A_{\mathrm{M}}$ indicates whether the attached membrane differs from the average membrane in its specific conductances.

Electrophysiology. Patch pipettes were pulled with a three-stage puller (Zeitz-Instrumente, Augsburg, Germany) from borosilicate glass capillaries with $1.5 \mathrm{~mm}$ external and $1.05 \mathrm{~mm}$ internal diameter (GB150T-10, Science Products GMBH, Hofheim, Germany) and fire-polished. They were coated with Sylgard to reduce their capacitance and to avoid the formation of a meniscus of extracellular solution disturbing the visualization of cells under the stereomicroscope (FS-60FC, Mitutoyo, Kawasaki, Japan). The pipette filling solution was (in mM): $140 \mathrm{KCl}, 1$ $\mathrm{CaCl}_{2}, 2 \mathrm{MgCl}_{2}, 10$ EGTA, 5 HEPES, adjusted to $\mathrm{pH} 7.3$ with $\mathrm{KOH}$. The resistance of the pipette was 2-3 M $\Omega$. The external solution consisted of (in mM): $135 \mathrm{NaCl}, 5.4 \mathrm{KCl}, 1.8 \mathrm{CaCl}_{2}, 1 \mathrm{MgCl}_{2}, 10$ D-glucose, $5 \mathrm{~mm}$ HEPES, adjusted to $\mathrm{pH} 7.4$ with $\mathrm{NaOH}$. All measurements were performed in the presence of $1.5 \mu \mathrm{M}$ tetrodotoxin (TTX; Sigma).

The patch-clamp recording system consisted of a single-electrode amplifier (SEC-10L, npi electronic GMBH, Tamm, Germany) and a computer running a homemade acquisition program. The current was sampled at $5 \mathrm{kHz}$ and filtered at $2 \mathrm{kHz}$ with a four-pole low-pass Bessel filter. Because of careful setting of the amplifier, the voltage error was below $5 \%$ as estimated with cell models. (The cell parameters were determined without filtering at a sampling frequency of $100 \mathrm{kHz}$.) Traces were corrected off-line for residual leak and capacitive currents as estimated from 20-40 mV hyperpolarizing voltage pulses from the holding potential. No inward rectifier currents were elicited during these pulses. The final current traces were obtained by averaging 20-50 sweeps. In the experiments in which TEA inhibition was investigated, the standard external solution was replaced through continuous perfusion with a solution with $10 \mathrm{~mm}$ TEA. The total amount of TEA solution perfused before recording was at least five times the volume of the chamber.

Recordings were undertaken at room temperature between 4 and $7 \mathrm{~d}$ after plating. Pyramidal-looking cells were preferred. Cell membrane parameters and access resistance were estimated by applying $20 \mathrm{mV}$ hyperpolarizing voltage pulses from a holding potential of $-80 \mathrm{mV}$ (Lindau and Neher, 1988). Because of the modest dendritic arborizations at this stage in culture, most neurons could be well simulated with a one-compartment equivalent circuit. In a few cases a two-compartment circuit was used. Typically the cell membrane capacitance was approximately $C_{\mathrm{M}}=10 \mathrm{pF}$. The capacitance was used to determine the effective area $A_{\mathrm{M}}=C_{\mathrm{M}} / c_{\mathrm{M}}$ with a specific capacitance $c_{\mathrm{M}}=1 \mu \mathrm{F} / \mathrm{cm}^{2}$. Only the experiments where the access resistance was $<20 \mathrm{M} \Omega$ were accepted. Access resistance and cell parameters were regularly monitored during the experiment and checked so that they remained constant. Voltages were not corrected for junction potentials, which were negligible for our purposes in these experimental conditions.

Transistor records. We used chips with an all-oxide surface with p-type field-effect transistors in n-type silicon (Fromherz et al., 1991). The area of a gate was $2.0 \times 2.4 \mu \mathrm{m}$. The fabrication of the chips was described previously (Weis et al., 1996; V. Kiessling, B. Müller, and P. Fromherz, unpublished observations). We kept the bulk silicon and the common source at a voltage $+1 \mathrm{~V}$ with respect to the bath. The drain-source voltage was $-0.5 \mathrm{~V}$. A voltage change by $+1 \mathrm{mV}$ on the gate induced a modulation of the source-drain current by $-0.02 \mu \mathrm{A}$. This working point was chosen to optimize the signal-to-noise ratio. The rms-noise was $\sim 100 \mu \mathrm{V}$ at a bandwidth of $10 \mathrm{kHz}$. We averaged $20-50$ records. There was a response only of those transistors that were precisely under the selected cell.

The specific seal conductance $g_{\mathrm{J}}$ between neuron and silicon was measured using an approach described previously (Vassanelli and Fromherz, 1997; Weis and Fromherz, 1997). Sinusoidal voltages (1000-1500 $\mathrm{Hz}, 3.5 \mathrm{mV} \mathrm{rms})$ were applied across the cell membrane $\left(V_{\mathrm{M}}\right)$ modulating the holding potential $(-80 \mathrm{mV})$. A lock-in amplifier (SR850, Stanford Research Systems, Sunnyvale, CA) was used to measure (1 Hz sampling rate) the corresponding voltages $\left(V_{\mathrm{J}}\right)$ in the neuron-silicon cleft detected by the transistor. The squared amplitude of the experimental transfer function $h=V_{\mathrm{J}} / V_{\mathrm{M}}$ was plotted against the squared angular frequency of the command voltage. The data were fitted by linear regression; the slope 


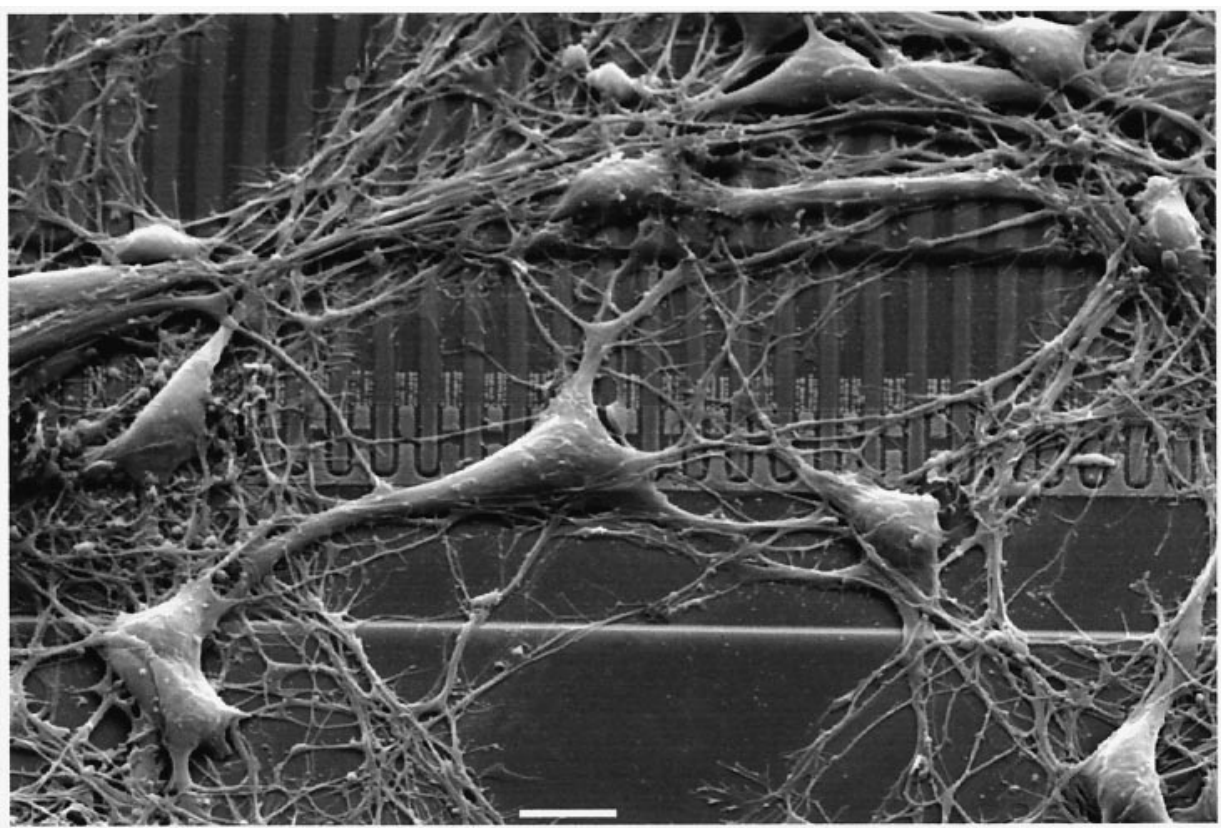

Figure 2. Scanning electron micrograph showing neurons from rat hippocampus cultured for $4 \mathrm{~d}$ in serum-free medium on a silicon chip with a silica surface coated with poly-L-lysine. Scale bar, $10 \mu \mathrm{m}$. The linear array of open transistors is seen in the center, with the drains and the lanes of field oxide directed upward and with the common source at the bottom. of the fit defined the square of a time constant $\tau_{\mathrm{J}} h_{\infty}$ (Vassanelli and Fromherz, 1997). The seal conductance was obtained from the relation $g_{\mathrm{J}}=c_{\mathrm{M}} / \tau_{\mathrm{J}} / h_{\infty}$ with $c_{\mathrm{M}}=1 \mu \mathrm{F} / \mathrm{cm}^{2}$.

Usually the transistor signals under voltage-clamp were fading away after a few minutes of recording. For that reason we could not measure families of voltage-dependent gating curves. Concomitantly, recordings of $\mathrm{AC}$ voltages decreased, too. This indicates that there was not a selective rundown of ionic currents, but that the coupling of the cell was getting worse because of an enhanced seal conductance $g_{\mathrm{J}}$, which may be caused by slight movements or by shrinking of a cell when contacted by the patch pipette.

\section{RESULTS}

\section{Culture on chip}

An electronmicrograph of a chip with neurons kept in serum-free medium for $4 \mathrm{~d}$ is shown in Figure 2. There were 96 transistors on the chip with a distance of $3.5 \mu \mathrm{m}$ in a linear array. The size of the voltage-sensitive gate areas was $2.0 \times 2.4 \mu \mathrm{m}$ (Weis et al., 1996; Kiessling, Müller, and Fromherz, unpublished observations). The diameter of a cell soma was $10-20 \mu \mathrm{m}$. One to three pyramidal neurons per chamber were well positioned on the array and well separated from other cells such that a defined transistor record could be expected. The distance between cell membrane and surface was in a range of $35-70 \mathrm{~nm}$ as determined by fluorescence interference contrast microscopy (Braun and Fromherz, 1998).

\section{A-type and K-type current}

We selected a neuron that was well placed on one of the transistors and made an electrical contact with a patch pipette in whole-cell configuration (Hamill et al., 1981; Sakmann and Neher, 1995). We applied an intracellular holding voltage of -50 $\mathrm{mV}$ and used a prepulse of $-110 \mathrm{mV}$ to remove the inactivation of the A-type and K-type potassium currents ("prepulse protocol") (Ficker and Heinemann, 1992). We activated the potassium conductances by applying a pulse to $+20 \mathrm{mV}$ and recorded the current through the pipette and the extracellular voltage on the transistor. Because of the noise of the transistor we had to average 20-50 signals. An example is shown in Figure 3. We observed a transient outward current that decayed within $40 \mathrm{msec}$ to an almost stationary current of $0.25 \mathrm{nA}$. Quite in contrast, the
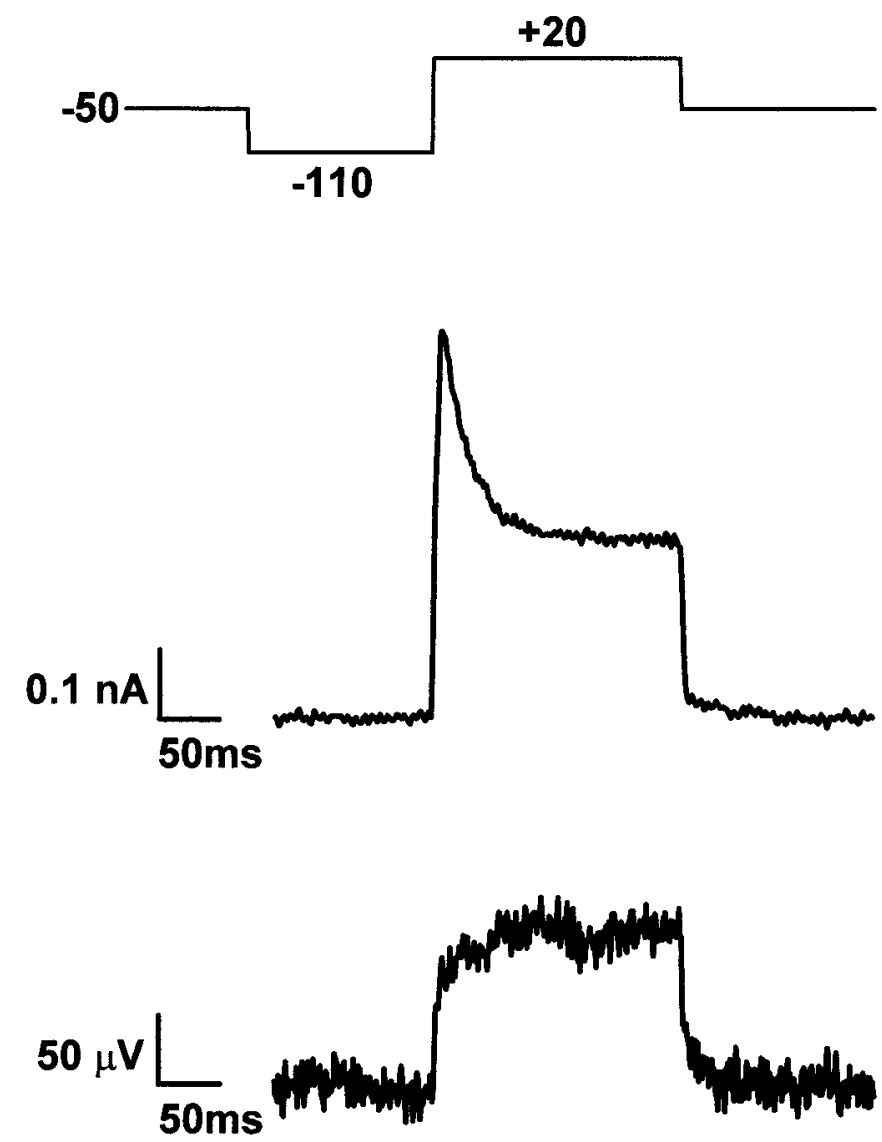

Figure 3. Voltage-clamp experiment of cultured neuron. Top, Protocol of intracellular voltage with a holding voltage of $-50 \mathrm{mV}$, a prepulse of $-110 \mathrm{mV}$, and an activation pulse of $+20 \mathrm{mV}$. Center, Whole-cell current with constant K-type signal and transient A-type component. Bottom, Transistor voltage with K-type signal and without A-type response. Shown is an average of 30 records. The interval between the records was $5 \mathrm{sec}$. 

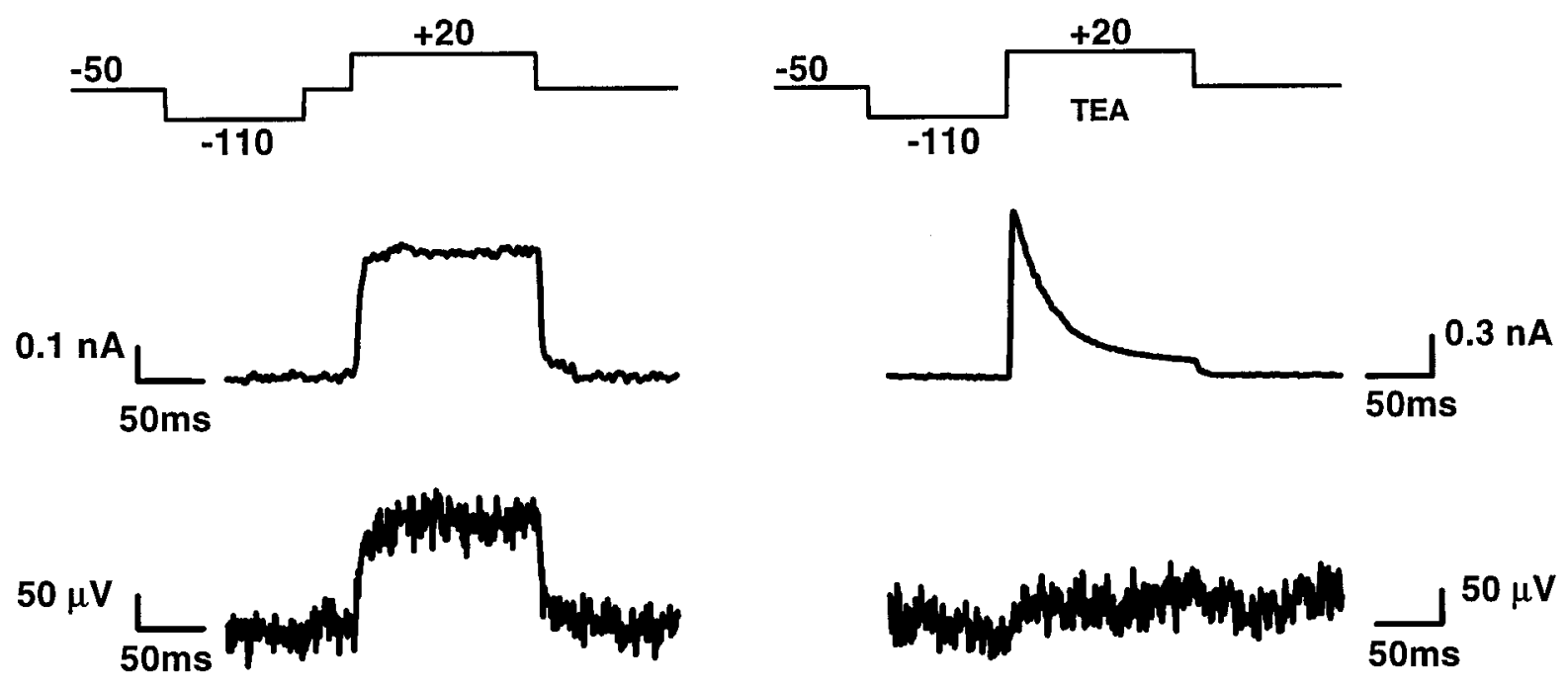

Figure 4. Voltage-clamp experiment was selective suppression of A-type current (left) and K-type current (right). Top, Protocol of intracellular voltage. Center, Whole-cell current. Bottom, Transistor voltage. The A-type signal is suppressed by application of a $50 \mathrm{msec}$ prepulse of $-50 \mathrm{mV}$ before activation $(l e f t)$. Nineteen records were averaged. The K-type signal is suppressed by application of $10 \mathrm{~mm}$ TEA (right). Twenty-five records were averaged. The interval between the records was $5 \mathrm{sec}$.

voltage on the transistor approached directly a stationary value of $+120 \mu \mathrm{V}$. No signal was detectable in neighboring transistors.

The response of the pipette current corresponds to the well known superposition of A-type and K-type potassium current with fast and slow inactivation, respectively (Numann et al., 1987; Ficker and Heinemann, 1992; Klee et al., 1995). Usually in our experiments an inactivation of the K-type current was hardly visible within $200 \mathrm{msec}$. The result may indicate that only a K-type conductance with very slow inactivation was expressed (Ficker and Heinemann, 1992). This K-type signal was recorded also by the transistor. However, there was no A-type component visible in the response of the transistor.

We suppressed the A-type current selectively by holding the cell for $50 \mathrm{msec}$ at $-50 \mathrm{mV}$ before activation of the potassium conductances ("delayed prepulse protocol") (Ficker and Heinemann, 1992). An example is shown in Figure 4. The record was from the same cell as that of Figure 3. Indeed there was no A-type transient in the pipette current, whereas the K-type current was unaffected. The record of the transistor was unchanged. The result proves that there was no A-type potassium current in the attached membrane. Of course, we cannot determine whether the channels responsible for A-type current are not present in the junction or whether their voltage sensitivity is blocked in the region of adhesion. We suppressed the K-type current selectively by extracellular application of $10 \mathrm{~mm}$ TEA (Ficker and Heinemann, 1992). An example is shown in Figure 4. We observed a typical A-type transient in the pipette current with inhibition of the K-type component. The transistor response was inhibited too. The result proves that the transistor record is indeed attributable to the channels that cause the usual K-type potassium current.

\section{Conductances}

We evaluated the conductances of the adhesion region and of the whole membrane from the data of Figure 3. The specific potassium conductance $\bar{g}_{\mathrm{M}}^{\mathrm{K}}$ of the cell membrane on average was obtained from the pipette current by division through the membrane area $A_{\mathrm{M}}$ and the driving potential $V_{\mathrm{M}}-K_{0}^{\mathrm{K}}$ according to Equation 2 with a reversal voltage $V_{0}^{\mathrm{K}}=-80 \mathrm{mV}$. From a
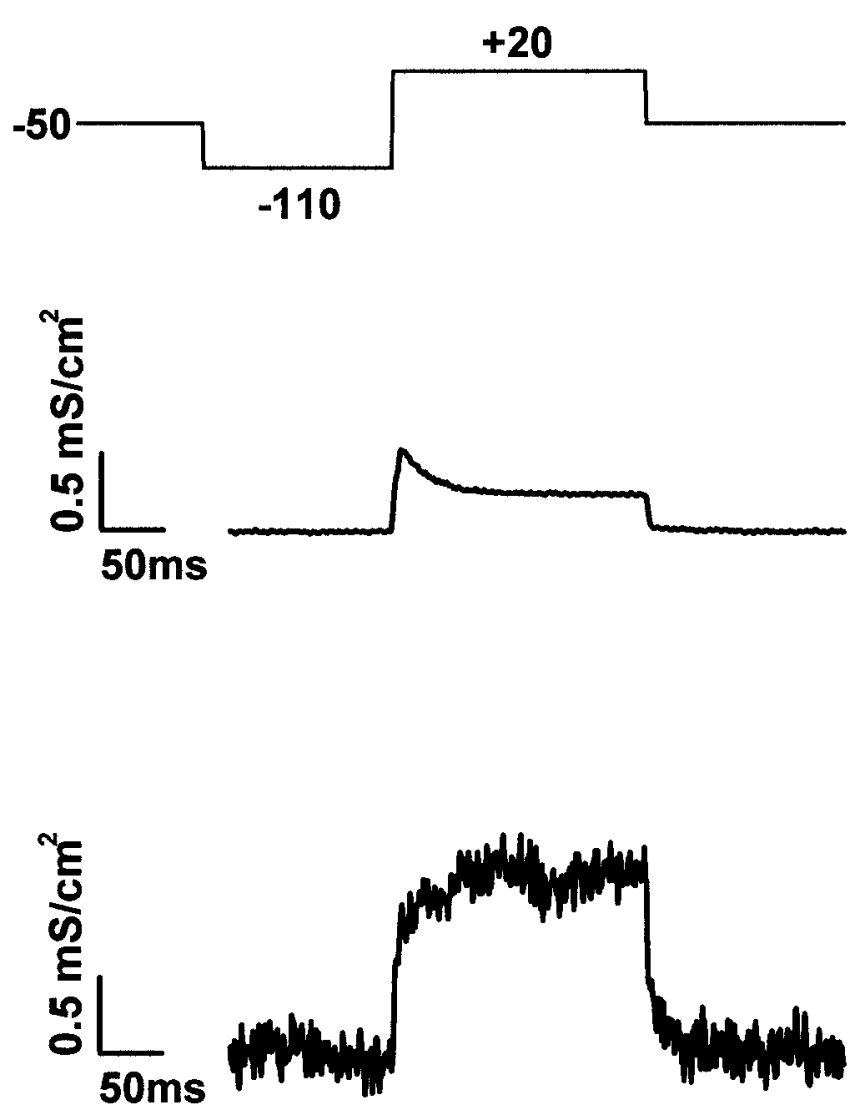

Figure 5. Specific membrane conductance. Top, Protocol of intracellular voltage. Center, Average specific potassium conductance $g_{\mathrm{M}}^{\mathrm{K}}$ of the cell membrane with K-type and A-type conductance. Bottom, Specific potassium conductance $g_{\mathrm{IM}}^{\mathrm{K}}$ of attached membrane region with enhanced K-type and without A-type conductance. Scaled records are from Figure 3. 
membrane capacitance $C_{\mathrm{M}}=11 \mathrm{pF}$ we obtained the area $A_{\mathrm{M}}=$ $1100 \mu \mathrm{m}^{2}$ using a specific capacitance $c_{\mathrm{M}}=1 \mu \mathrm{F} / \mathrm{cm}^{2}$. The result is shown in Figure 5. The amplitude of the transient A-type conductance was $\bar{g}_{\mathrm{M}}^{\mathrm{K}(\mathrm{A})}=0.24 \mathrm{mS} / \mathrm{cm}^{2}$. The stationary K-type conductance was $\bar{g}_{\mathrm{M}}^{\mathrm{K}(\mathrm{K})}=0.21 \mathrm{mS} / \mathrm{cm}^{2}$. These relatively low values are attributable to the short time the cells are held in culture. It should also be considered that the lack of astroglia in serum-free culture may impair the expression of channels (McFarlane and Cooper, 1993; Wu and Barish, 1994).

The specific potassium conductance $g_{\mathrm{JM}}^{\mathrm{K}}$ in the attached membrane was obtained from the transistor voltage by multiplication with the specific conductance $g_{\mathrm{J}}$ of the cleft and by division through $V_{\mathrm{M}}-V_{0}^{\mathrm{K}}$ according to Equation 1. The result is shown in Figure 5 with $g_{\mathrm{J}}=1000 \mathrm{mS} / \mathrm{cm}^{2}$ as obtained from AC measurements for that particular cell. There was no significant A-type conductance in the attached membrane with $g_{\mathrm{JM}}^{\mathrm{K}(\mathrm{A})} \approx 0$. The stationary K-type conductance in the junction was $g_{\mathrm{M}}^{\mathrm{K}(\mathrm{K})}=1.2$ $\mathrm{mS} / \mathrm{cm}^{2}$. The ratio of conductance in attached membrane and average membrane was $g_{\mathrm{JM}}^{\mathrm{K}(\mathrm{K})} / \bar{g}_{\mathrm{M}}^{\mathrm{K}(\mathrm{K})}=5.7$.

The specific conductance of the junction depends on the geometry of adhesion by the relation $g_{\mathrm{J}}=5 d_{\mathrm{J}} / \rho_{\mathrm{J}} a_{\mathrm{J}}^{2}$ with the distance $d_{\mathrm{J}}$ of membrane and substrate, the radius $a_{\mathrm{J}}$ of a circular adhesion area, and the specific resistance $a_{\mathrm{J}}$ of the extracellular medium in the region of adhesion (Vassanelli and Fromherz, 1997; Weis and Fromherz, 1997). The measured conductance $g_{\mathrm{J}}=1000 \mathrm{mS} / \mathrm{cm}^{2}$ corresponds to a circular junction with $a_{\mathrm{J}}=6 \mu \mathrm{m}$ at a distance $d_{\mathrm{J}}=60 \mathrm{~nm}$ - estimated from fluorescence interference contrast microscopy (Braun and Fromherz, 1998) - and a specific resistence $\rho_{\mathrm{J}}=80 \Omega \mathrm{cm}$ as in the bulk electrolyte, in good agreement with the actual shape of the cells (Fig. 1). The effective area of adhesion was then $A_{\mathrm{JM}}=110 \mu \mathrm{m}^{2}$. There were approximately 55 channels in a junction with a channel conductance of $20 \mathrm{pS}$ (Storm, 1990; Bossu and Gähwiler, 1996).

The ratio $g_{\mathrm{JM}}^{\mathrm{K}(\mathrm{K})} / g_{\mathrm{FM}}^{\mathrm{K}(\mathrm{K})}$ of specific conductance in the attached membrane and free membrane may be considerably larger than the ratio $g_{\mathrm{JM}}^{\mathrm{K}(\mathrm{K})} / \bar{g}_{\mathrm{M}}^{\mathrm{K}(\mathrm{K})}=5$.7. With the fraction of attached area $\alpha=$ $A_{\mathrm{JM}} / A_{\mathrm{M}}$ and the general relation $\bar{g}_{\mathrm{M}}=\alpha g_{\mathrm{JM}}+(1-\alpha) g_{\mathrm{FM}}$ we obtain with $A_{\mathrm{JM}}=110 \mu \mathrm{m}^{2}$ and $A_{\mathrm{M}}=1100 \mu \mathrm{m}^{2}$ a factor of enhancement $g_{\mathrm{JM}}^{\mathrm{K}(\mathrm{K})} / g_{\mathrm{FM}}^{\mathrm{K}(\mathrm{K})}=12$.

A successful experiment required a good whole-cell contact, a sufficient A-type and K-type current, and a tight contact between cell and transistor. In that sense we obtained successful records with 10 neurons where the specific seal conductance $g_{\mathrm{J}}$ was between 600 and $1700 \mathrm{mS} / \mathrm{cm}^{2}$. The suppression of the A-type conductance was complete in six cells and partial in three cells. In one case we observed an enhancement of the A-type conductance. The K-type conductance was enhanced in all cases with $g_{\mathrm{JM}}^{\mathrm{K}(\mathrm{K})} / \bar{g}_{\mathrm{M}}^{\mathrm{K}(\mathrm{K})}$ in a range between 1.5 and 6 . A correlation of the results with the age of the cells in culture was not observed.

The whole-cell records may include a contribution of proximal dendrites with an enhanced A-type current there (Hoffman et al., 1997), although the arborization was modest in our culture. We determined, however, that somatic A-type current did exist in our cells by taking nucleated patched from the upper side of cell somata (Rizzo and Nonner, 1992; Hoffman et al., 1997; Martina et al., 1998). Thus the data indeed indicate a depletion of somatic A-type conductance in the junction.

We repeated the experiments on chips coated with fibronectin to determine whether the supression of A-type and the enhancement of K-type current was related to the chemical nature of adhesion. With respect to K-type conductance we found a similar effect as on poly-lysine in all eight neurons recorded. The A-type conductance appeared with a delay in these cultures. It was expressed clearly only in one of the eight cells studied. In that case the A-type conductance was completely suppressed.

\section{DISCUSSION}

We used a new electrophysiological approach to characterize the adhesion region of rat hippocampal neurons in culture under voltage-clamp. The conductance of the attached membrane was probed by a field-effect transistor in the substrate. In parallel the conductance of the whole-cell membrane was observed by conventional whole-cell patch-clamp technique. We focused our attention on two well characterized potassium currents, the A-type (transient) and the K-type (sustained). By comparing the transistor records with the whole-cell records we found that the A-type conductance was highly depleted in the region of adhesion and that the K-type conductance was enhanced there. A similar distribution was observed in neurons cultured on both poly-lysine and fibronectin.

Our results are compatible with observations by Rizzo and Nonner (1992) who found that in membrane spheres ("blebs") excised from the soma of cultured neurons from hippocampus, the A-type conductance was present in the membrane blebs whereas the K-type conductance was low. We may infer that in cultured neurons the voltage-gated channels responsible for the A-type and K-type conductances are distributed differently in the somatic membrane, the K-type channels being preferentially in the adhesion region and the A-type channels in the free membrane. Interestingly the Kv2.1 channel, identified as a major contributor to the K-type conductance in hippocampal neurons (Murakoshi and Trimmer, 1999), has been shown to be preferentially localized at cell-cell or cell-substrate adhesion zones using immunostaining (Sharma et al., 1993; Scannevin et al., 1996; Du et al., 1998). Therefore the Kv2.1 channel may be considered a possible candidate for the enhancement of the K-type conductance in the adhesion region of cultured hippocampal neurons. How the ion channels become localized in the right domain of the membrane is still an open question. Increasing evidence suggests that adhesion interactions could play a pivotal role, with a direct or indirect binding of ion channels to extracellular adhesion molecules (Isom et al., 1995; Irie et al., 1997; Sheng and Wyszynski, 1997; Thomas et al., 1997; Zito et al., 1997). The fact that switching from poly-lysine to fibronectin did not change substantially the distribution pattern of potassium conductances could suggest that highly specific adhesion interactions are required to localize and cluster ion channels.

Another possibility is that the channel molecules are distributed homogeneously all over the somatic membrane but that their activity is regulated differently in the two domains. A direct effect of poly-lysine on channel activity is unlikely because neurons cultivated on fibronectin showed a similar distribution of conductances. However, there may be a modulation from the intracellular side. One might argue that the depletion of A-type and the enhancement of K-type conductance is only apparent because the fast inactivation of A-type channels is inhibited selectively in the adhesion region such that a sustained conductance appears that mimics the K-type conductance. However, we showed that TEA, a specific blocker of the K-type conductance, is able to suppress completely the sustained conductance in the adhesion region.

The localization of ion conductances in specific domains of a neuronal membrane is essential for electrical signaling. A-type 
and K-type potassium conductances represent a good example because their different distribution in somata and neuronal processes could account for a modulation of the propagation of action potential and of the integrative properties of a neuron (Storm, 1990; Debanne et al., 1997; Hoffman et al., 1997; Magee, 1998; Martina et al., 1998). On the other hand it should be considered that the major role of the attached membrane of cultured neurons could be to control cell migration rather than to contribute to an electrical integrative function. Therefore in this region, well protected from synaptic contacts, the peculiar distribution of potassium conductances found in this study could be important for cell motility. In fact, it has been proposed that potassium conductances are involved in the migration process of embryonic neurons during development (Hallows and Tempel, 1998).

In respect to the complex adhesion interactions in a tissue, neurons cultivated on adhesion molecules on inert silica represent a simple experimental system. The neuronal membrane in its adhesion region interacts with defined adhesion molecules, and their effect on the ion conductances can be investigated by a direct electrophysiological measurement. Transistor recording opens a way to study targeting and modulation of ion channels in a plasma membrane as a function of their interactions with adhesion molecules. An improvement of the signal-to-noise ratio will be important to avoid signal averaging and to detect the noise of channel dynamics in the region of adhesion.

Accumulation and depletion of ion channels in the region of an extracellular electrode determines the magnitude and shape of the extracellular record of an action potential (Schätzthauer and Fromherz, 1998; Vassanelli and Fromherz, 1998; Fromherz, 1999). Because A-type and K-type potassium channels have distinct effects on the shape of an action potential, a selective accumulation and depletion - as we detected it now-affects the shape of extracellular records in culture and in brain tissue.

\section{REFERENCES}

Banker GA, Cowan WM (1977) Rat hippocampal neurons in dispersed cell culture. Brain Res 126:397-425.

Bossu JL, Gähwiler BH (1996) Distinct modes of channel gating underlie inactivation of somatic $\mathrm{K}^{+}$current in rat hippocampal cells in vitro. J Physiol (Lond) 495:383-397.

Braun D, Fromherz P (1998) Fluorescence interferometry of neuronal cell adhesion on microstructured silicon. Physiol Rev Lett 81:5241-5244.

Brewer GJ, Torricelli JR, Evege EK, Price PJ (1993) Optimized survival of hippocampal neurons in B27-supplemented neurobasal, a new serum-free combination. J Neurosci Res 35:567-576.

Debanne D, Guerineau NC, Gähwiler BH, Thompson SM (1998) Action-potential propagation gated by an axonal $\mathrm{I}_{\mathrm{A}}$-like $\mathrm{K}^{+}$conductance in hippocampus. Nature 389:286-289.

Du J, Tao-Chang J-H, Zerfas P, McBain CJ (1998) The $\mathrm{K}^{+}$channel, $\mathrm{Kv} 2.1$, is apposed to astrocytic processes and is associated with inhibitory postsynaptic membranes in hippocampal and cortical principal neurons and inhibitory interneurons. Neuroscience 84:37-48.

Evans MS, Collings MA, Brewer GJ (1998) Electrophysiology of embryonic, adult and aged rat hippocampal neurons in serum-free culture. J Neurosci Methods 79:37-46.

Ficker E, Heinemann U (1992) Slow and fast transient potassium currents in cultured rat hippocampal cells. J Physiol (Lond) 445:431-455.

Fromherz P (1999) Extracellular recording with transistors and the distribution of ionic conductances in a cell membrane. Eur Biophys $\mathrm{J}$ 28:254-258.

Fromherz P, Offenhäusser A, Vetter T, Weis J (1991) A neuron-silicon junction: a Retzius-cell of the leech on an insulated-gate field-effect transistor. Science 252:1290-1293.
Fromherz P, Müller CO, Weis R (1993) Neuron-transistor: electrical transfer function measured by the patch-clamp technique. Phys Rev Lett 71:4079-4082.

Hallows JL, Tempel BL (1998) Expression of Kv1.1, a Shaker-like potassium channel, is temporally regulated in embryonic neurons and glia. J Neurosci 18:5682-5691.

Hamill OP, Marty A, Neher E, Sakmann B, Sigworth FJ (1981) Improved patch-clamp techniques for high-resolution current recording from cells and cell-free membrane patches. Pflügers Arch 391:85-100.

Hoffman DA, Magee JC, Colbert CM, Johnston D (1997) $\mathrm{K}^{+}$channel regulation of signal propagation in dendrites of hippocampal pyramidal neurons. Nature 387:869-875.

Irie M, Hata Y, Takeuchi M, Ichtchenko K, Toyoda A, Hirao K, Takai Y, Rosahl TW, Südhof TC (1997) Binding of neuroligins to PSD-95. Science 277:1511-1514.

Isom LL, Ragsdale DS, De Jongh KS, Westenbroek RE, Reber BFX, Scheuer T, Catterall WA (1995) Structure and function of the $\beta 2$ subunit of brain sodium channels, a transmembrane glycoprotein with a CAM motif. Cell 83:433-442.

Klee R, Ficker E, Heinemann U (1995) Comparison of voltagedependent potassium currents in rat pyramidal neurons acutely isolated from hippocampal regions CA1 and CA3. J Neurophysiol 74:1982-1995.

Klee R, Eder C, Ficker E, Heinemann U (1997) Age dependent variations in potassium sensitivity of A-currents in rat hippocampal neurons. Eur J Neurosci 9:1970-1976.

Lindau M, Neher E (1988) Patch-clamp techniques for time-resolved capacitance measurements in single cells. Pflügers Arch 411:137-146.

Magee JC (1998) Dendritic hyperpolarization-activated currents modify the integrative properties of hippocampal CA1 pyramidal neurons. J Neurosci 18:7613-7624.

Maletic-Savatic M, Lenn NJ, Trimmer JS (1995) Differential spatiotemporal expression of $\mathrm{K}^{+}$channel polypeptides in rat hippocampal neurons developing in situ and in vitro. J Neurosci 15:3840-3851.

Martina M, Schultz JH, Ehmke H, Monyer H, Jonas P (1998) Functional and molecular differences between voltage-gated $\mathrm{K}^{+}$channels of fastspiking interneurons and pyramidal neurons of rat hippocampus. J Neurosci 18:8111-8125.

McFarlane S, Cooper E (1993) Extrinsic factors influence the expression of voltage-gated $\mathrm{K}$ currents on neonatal rat sympathetic neurons. J Neurosci 13:2591-2600.

Murakoshi H, Trimmer JS (1999) Identification of the Kv2.1 K $\mathrm{K}^{+}$channel as a major component of the delayed rectifier $\mathrm{K}^{+}$current in rat hippocampal neurons. J Neurosci 19:1728-1735.

Numann RE, Wadman WJ, Wong RKS (1987) Outward currents of single hippocampal cells obtained from the adult guinea-pig. J Physiol (Lond) 393:331-353.

Rizzo MA, Nonner W (1992) Transient K current in the somatic membrane of cultured central neurons of embryonic rat. J Neurophysiol 68:1708-1719.

Rothman S, Cowan WM (1981) A scanning electron microscope study of the in vitro development of dissociated hippocampal cells. J Comp Neurol 195:141-155.

Sakmann B, Neher E (1995) Single channel recording, Ed 2. New York: Plenum.

Scannevin RH, Murakoshi H, Rhodes KJ, Trimmer JS (1996) Identification of a cytoplasmatic domain important in the polarized expression and clustering of the Kv2.1 $\mathrm{K}^{+}$channel. J Cell Biol 135:1619-1632.

Schätzthauer R, Fromherz P (1998) Neuron-silicon junction with voltage-gated ionic currents. Eur J Neurosci 10:1956-1962.

Segal M, Barker JL (1984) Rat hippocampal neurons in culture: potassium conductances. J Neurophysiol 51:1409-1433.

Segal M, Rogawski MA, Barker JL (1984) A transient potassium conductance regulates the excitability of cultured hippocampal and spinal neurons. J Neurosci 4:604-609.

Sharma N, D'Arcangelo G, Kleinklaus A, Halegoua S, Trimmer JS (1993) Nerve growth factor regulates the abundance and distribution of $\mathrm{K}^{+}$channels in PC12 cells. J Cell Biol 123:1835-1843.

Sheng M, Wyszynski M (1997) Ion channel targeting in neurons. BioEssays 19:847-853.

Sheng M, Tsaur ML, Jan YN, Jan LY (1992) Subcellular segregation of two A-type $\mathrm{K}^{+}$channel proteins in rat central neurons. Neuron 9:271-284.

Sheng M, Tsaur ML, Jan YN, Jan LY (1994) Contrasting subcellular localization of the Kv1.2 $\mathrm{K}^{+}$channel subunit in different neurons of rat brain. J Neurosci 14:2408-2417. 
Storm JF (1990) Potassium currents in hippocampal pyramidal cells. Prog Brain Res 83:161-187.

Thomas U, Kim E, Kuhlendahl S, Ho Koh Y, Gundelfinger ED, Sheng M, Garner CC, Budnik V (1997) Synaptic clustering of the cell adhesion molecule fasciclin II by discs-large and its role in the regulation of presynaptic structure. Neuron 19:787-799.

Vassanelli S, Fromherz P (1997) Neurons from rat brain coupled to transistors. Appl Phys A 65:85-88.

Vassanelli S, Fromherz P (1998) Transistor-records of excitable neurons from rat brain. Appl Phys A 66:459-463.

Veh RW, Lichtinghagen R, Sewing S, Wunder F, Grumbach IM, Pongs O (1995) Immunohistochemical localization of five members of the $\mathrm{K}_{\mathrm{v}} 1$ channel subunits: contrasting subcellular locations and neuron-specific co-localizations in rat brain. Eur J Neurosci 7:2189-2205.

Weis R, Fromherz P (1997) Frequency dependent signal-transfer in neuron-transistors. Phys Rev E 55:877-889.

Weis R, Müller B, Fromherz P (1996) Neuron-adhesion on a silicon chip probed by an array of field-effect transistors. Phys Rev Lett 76:327-330.

Wu RL, Barish ME (1994) Astroglial modulation of transient potassium current development in cultured mouse hippocampal neurons. J Neurosci 14:1677-1687.

Zito K, Fetter RD, Goodman CS, Isacoff EY (1997) Synaptic clustering of fasciclin and shaker; essential targeting sequences and role of Dlg. Neuron 19:1007-1016. 